University of Nebraska - Lincoln DigitalCommons@University of Nebraska - Lincoln

2017

\title{
Monte Carlo simulation of a Knudsen effusion mass spectrometer sampling system
}

Michael J. Radke

Johns Hopkins University

Nathan S. Jacobson

NASA Glenn Research Center, nathan.s.jacobson@nasa.gov

Evan H. Copland

CSIRO Clayton

Follow this and additional works at: http://digitalcommons.unl.edu/nasapub

Radke, Michael J.; Jacobson, Nathan S.; and Copland, Evan H., "Monte Carlo simulation of a Knudsen effusion mass spectrometer sampling system" (2017). NASA Publications. 258.

http://digitalcommons.unl.edu/nasapub/258

This Article is brought to you for free and open access by the National Aeronautics and Space Administration at DigitalCommons@University of Nebraska - Lincoln. It has been accepted for inclusion in NASA Publications by an authorized administrator of DigitalCommons@University of Nebraska - Lincoln. 


\title{
Monte Carlo simulation of a Knudsen effusion mass spectrometer sampling system
}

\author{
Michael J. Radke ${ }^{1}$, Nathan S. Jacobson ${ }^{2 \star}$ (D) and Evan H. Copland ${ }^{3}$ \\ ${ }^{1}$ Johns Hopkins University, Baltimore, MD 21218, USA \\ ${ }^{2}$ NASA Glenn Research Center, Cleveland, $\mathrm{OH} 44135$, USA \\ ${ }^{3}$ CSIRO Clayton, VIC 3168, Australia
}

RATIONALE: Knudsen effusion mass spectrometry (KEMS) shows improved performance with the "restricted collimation" method of Chatillon and colleagues, which consists of two apertures between the Knudsen cell orifice and the ionizer. These apertures define the shape and position of the molecular beam independently of the sample and effusion orifice and as a result reduce background and improve sampling from the Knudsen cell. Modeling of the molecular beam in restricted collimation allows optimization of the apertures' diameters and spacing.

METHODS: Knudsen flow is easily simulated with a Monte Carlo method. In this study a Visual Basic for Excel (VBA) code is developed to simulate the molecular beam originating from a vaporizing condensed phase in a Knudsen cell and passing through the cell orifice and the two apertures.

RESULTS: The code is able to calculate the transmission coefficient through the cell orifice, through the cell orifice and the first aperture, and through the cell orifice and first and second apertures. Also calculated are the angular distributions of the effusate density emerging from the cell and average number of collisions with the orifice walls.

CONCLUSIONS: This code allows the geometry (aperture spacing and diameters) of the sampling system to be optimized for maximum transmission. The calculated effusate distributions and low average number of orifice wall collisions illustrated the advantages of restricted collimation. Calculated transmission factors are also compared to literature values calculated via the analytical method of Chatillon and colleagues. Published in 2017. This article is a U.S. Government work and is in the public domain in the USA.

Knudsen effusion mass spectrometry (KEMS) is a well-established technique for sampling high-temperature vapors from a Knudsen cell. ${ }^{[1-3]}$ A Knudsen cell is a small enclosure which holds a condensed phase sample. The cell is heated uniformly, and an equilibrium vapor develops above the condensed phase. The effusion orifice has a well-defined geometry and in all types of KEMS systems the effusion orifice directs a molecular beam composed of the vapor above the condensed phase into the ionizer of a mass spectrometer. The requirements for Knudsen sampling include a cell orifice with a Knudsen number (ratio of the mean free path to orifice diameter) of 10 or greater. Thus molecule wall collisions dominate over molecule-molecule collisions, and the vapor in the molecular beam is representative of the vapor above the condensed phase.

Recently, Chatillon and coworkers have discussed a novel method of sampling from a Knudsen cell. ${ }^{[4-7]}$ Their method is termed "restricted collimation" and involves two collimating apertures above the cell effusion orifice. The first is in the plate that separates the Knudsen cell chamber from the ionizer chamber. Chatillon terms this the "field aperture". The field aperture is necessarily smaller than the Knudsen cell orifice, so that the ionizer effectively 'sees' only the inside of the Knudsen cell. The second aperture is directly below the

* Correspondence to: N. S. Jacobson, Materials and Structures, NASA Glenn Research Center, Cleveland, $\mathrm{OH} 44135$, USA.

E-mail: nathan.s.jacobson@nasa.gov ionizing filament and is termed the "source aperture". The advantages of this restricted collimation configuration is that unwanted vapor from the heat shields and furnace parts is minimized, as ideally only material from the cell is sampled. Such sampling is particularly useful in multi-cell instruments, to limit cross-over of molecular beams from adjacent cells.

Chatillon and coworkers have modeled restricted collimation ${ }^{[4-7]}$ with equations analogous to the decay of light intensity. Molecular beams are analogous to transmission of light, a stream of photons. Many of the equations developed for light are readily applicable to these molecular beams. First, note that the flux decays as $1 / a^{2}$, where $a$ is the distance from the source to the receiver. The basic equations for flux received from a radiating element are derived in the paper and textbook by Walsh. ${ }^{[8,9]}$ The problem germane to the collimation of a molecular beam in mass a spectrometer is in the transmission of the beam from one disk source to another co-axial disk. The molecular flow, $J$, emitted from disk 1 and passing through disk 2 is given by:

$J\left(r_{1}, r_{2}, c\right)=\frac{p}{\sqrt{2 \pi M R T}} \frac{\pi}{2}\left[\left(r_{1}^{2}+r_{2}^{2}+c^{2}\right)-\sqrt{\left(r_{1}^{2}+r_{2}^{2}+c^{2}\right)-4 r_{1}^{2} r_{2}^{2}}\right]$

Here $c$ is the distance between the two disks, $r_{1}$ is the radius of the radiating disk, and $r_{2}$ is radius of the receiving disk. Also, $p$ is the partial pressure of the vapor source, $M$ is the molecular weight of the vapor species, $R$ is the gas constant, and $T$ is the absolute temperature. The expression on the right hand side of Eqn. (1) is the basic Hertz-Knudsen-Langmuir expression for 
vapor flux per unit surface on the whole space above a surface ( $2 \pi$ steradians) and the rest of the expression is a retarding factor on the flux. The study of Morland et al. ${ }^{[4]}$ is based on the supposition that the aperture sizes and separation
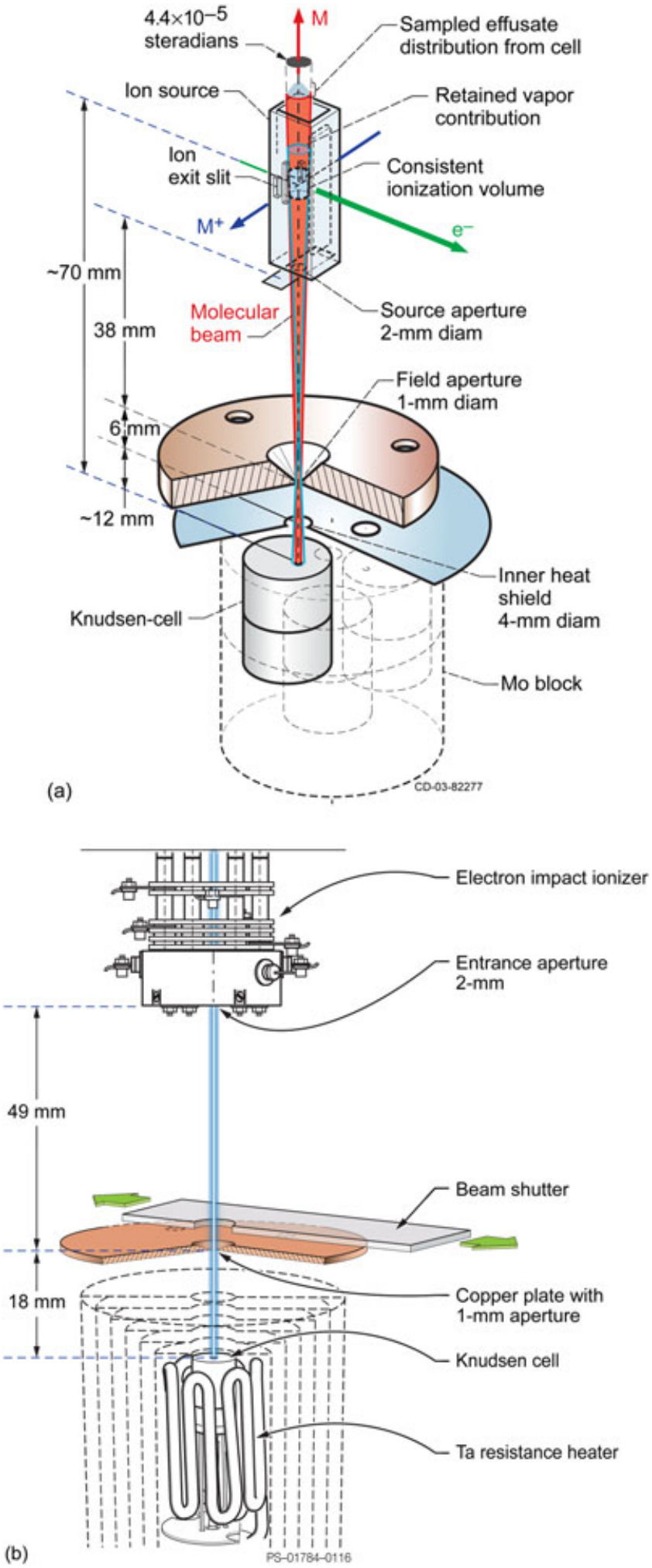

Figure 1. Restricted collimation sampling for (a) magnetic sector Knudsen effusion mass spectrometer and (b) quadrupole Knudsen effusion mass spectrometer. [Color figure can be viewed at wileyonlinelibrary.com] determine the transmission, regardless of the emitting surface. A second set of calculations ${ }^{[6,7]}$ are based on calculating the total emission of molecules from the penumbra section, below the effusion orifice, to the umbra diameter, which is the upper aperture. Their latest calculations ${ }^{[7]}$ and this study confirm Morland's original supposition.

The two KEMS instruments at the NASA Glenn Research Center have been adapted for restricted collimation. The configuration from the cell to the ionizer is illustrated in Figs. 1(a) and 1(b) for the magnetic sector instrument ${ }^{[2]}$ and the quadrupole instrument, respectively. For both instruments, the Knudsen cell furnace chamber and ionizer chamber are separated by a copper plate. The field aperture in this plate is adjustable with a secondary piece for accurate alignment with the source aperture, using a laser.

Knudsen flow through pipes has been described analytically by many investigators (see, e.g.: ${ }^{[10,11]}$ ). In 1960, Davis published a Monte Carlo simulation of Knudsen flow in pipes. ${ }^{[12]}$ Since then, many investigators have further extended this Monte Carlo approach. ${ }^{[12-19]}$ Today, because of the wide availability of high-speed desktop computers with multicore processors, Monte Carlo simulation is one of the easiest and most flexible ways to describe Knudsen flow.

In this report a Monte Carlo Knudsen flow simulation for pipes is adapted to model the vaporization of the condensed phase in the cell through the cell orifice and the two apertures. The code was adapted from an earlier FORTRAN code ${ }^{[18]}$ to Microsoft Visual Basic for Excel (VBA). Thus the code is readily run on any personal computer. It is very flexible, so that the various aperture diameters and distances can be adjusted to maximize molecular beam transmission. Apertures can be added or removed to calculate basic transmission through a channel or transmission through several apertures. We briefly discuss code and the inclusion of collimating apertures. Sample calculations are presented and compared with those from the analytical approach.

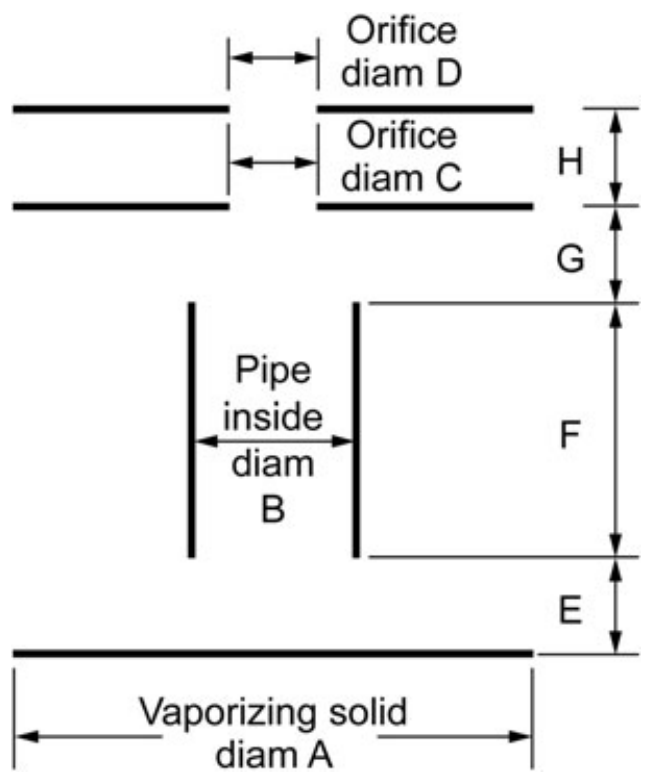

Figure 2. Two-dimensional representation of the simulated restricted collimation sampling system. 


\section{MONTE CARLO CODE}

As noted, many investigators have written Monte Carlo codes to simulate Knudsen flow. ${ }^{[12-19]}$ Molecule-molecule collisions are minimal and hence the linear trajectory of each molecule can be traced individually until it either exits the upper orifice or goes out of the beam before that. The details of the code are discussed in the companion report to this paper. ${ }^{[19]}$

Figure 2 is a two-dimensional representation of the restricted collimation system we modeled. The orifice is given a finite length, whereas the two apertures are treated as infinitely thin. For this study the effusion orifice and two apertures are co-axial. All dimensions are in $\mathrm{mm}$. The modeling code can be summarized as follows:

1. Set a random starting point on the vaporizing surface.

2. Molecule leaves surface with direction following cosine distribution. The direction cosines define the trajectory. In the analytical model, the flux leaving this surface and reaching the upper aperture is given by Eqn. (1).

3. Determine if the molecule enters pipe (orifice) or not. The molecule may strike the wall of pipe or it may exit pipe.

4. If molecule strikes wall, then it leaves again and would either exit the top of the pipe, collide with wall again, or exit the bottom of the pipe. Following Davis, ${ }^{[12]}$ this decision is based on the shortest distance to the wall, bottom, or top.

5. Molecules which exit the top of the pipe are allowed to continue their trajectory to see if they pass through the field and then the source aperture. This is determined by calculation of the molecule's coordinates from the direction cosines in the plane of the particular aperture. Then the coordinates are tested to see if these fall in the actual aperture.

6. Molecules which exit the bottom of the pipe or do not pass through the apertures are discarded.

7. The output of the code gives the transmission factor, which is defined as the number of escapes divided by total

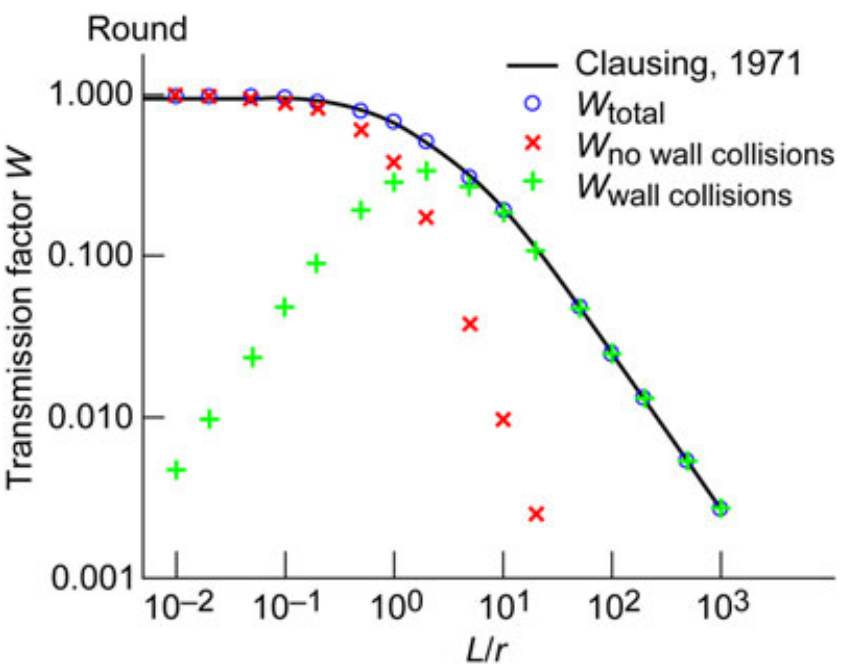

Figure 3. Plot of transmission factor vs length-to-radius ratio for a cylindrical channel. Also shown are the transmission factors for molecules which pass through the channel with and without collisions. [Color figure can be viewed at wileyonlinelibrary.com] number of molecular 'flights'. In our model we define the vaporizing surface (a flat surface in the Knudsen cell) at the base of the pipe or a short distance below the pipe. Each molecule leaving this surface constitutes a 'flight'. Transmission factors are reported for the pipe, for the pipe and field aperture, and for the pipe, field aperture and source aperture. In addition angular distributions can be determined and number of pipe/wall collisions can be tabulated.

\section{RESULTS}

\section{Knudsen flow through a channel}

In order to validate the code, a series of calculations were conducted through cylindrical and rectangular pipes. The results were compared with well-documented data for transmission through these geometries. Transmission factors through cylindrical and rectangular channels have been calculated for a variety of geometries and show good agreement with tabulated transmission factors, as shown in Figs. 3 and $4 .^{[20-22]}$ The Monte Carlo method further allows a transmission factor to be determined for molecules which pass through the channel with and without wall collisions. Thus three transmission factors are shown in Figs. 3 and 4.

Figure 5 shows the angular distribution of molecules effusing from cylindrical channels with various length-toradius ratios $[l / r]$. To create these plots, molecules are sorted into one-degree bins according to the angle they make with the $x$ (central) axis as they exit the channel. These counts are then divided by the unit of solid angle so they represent molecules per unit solid angle. They are normalized to the highest count, which is along the central axis. The $l / r$ of the channel has a strong effect on the distribution of exiting molecules, with large $l / r$ creating a narrow beam of molecules, as opposed to the near ideal Cosine Law distribution of very low $l / r$. These results are consistent with the analytical calculations of Grimley et al. ${ }^{[11]}$

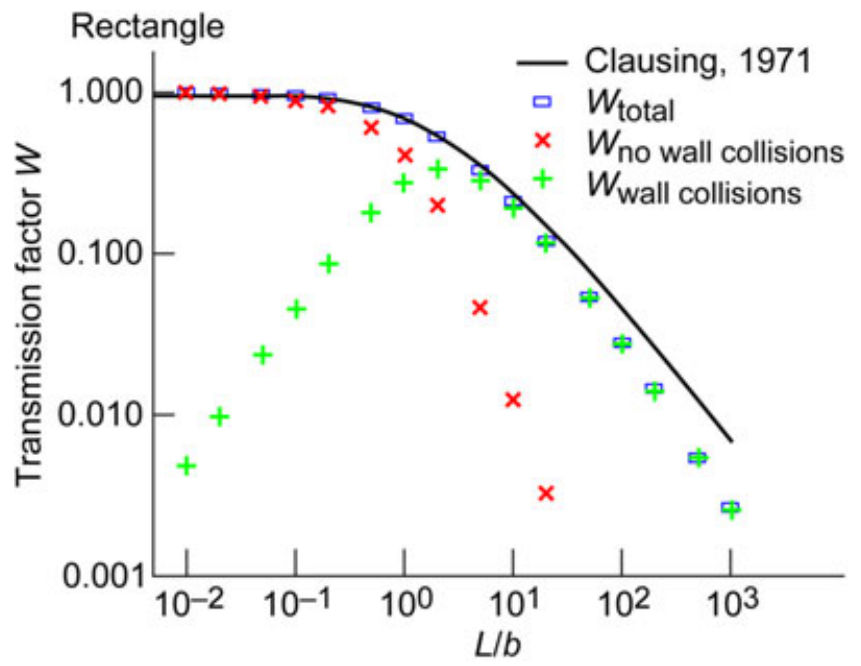

Figure 4. Plot of transmission factors vs length-to-width ratio for a rectangulare channel. Also shown are the transmission factors for molecules which pass through the channel with and without collisions. [Color figure can be viewed at wileyonlinelibrary.com] 


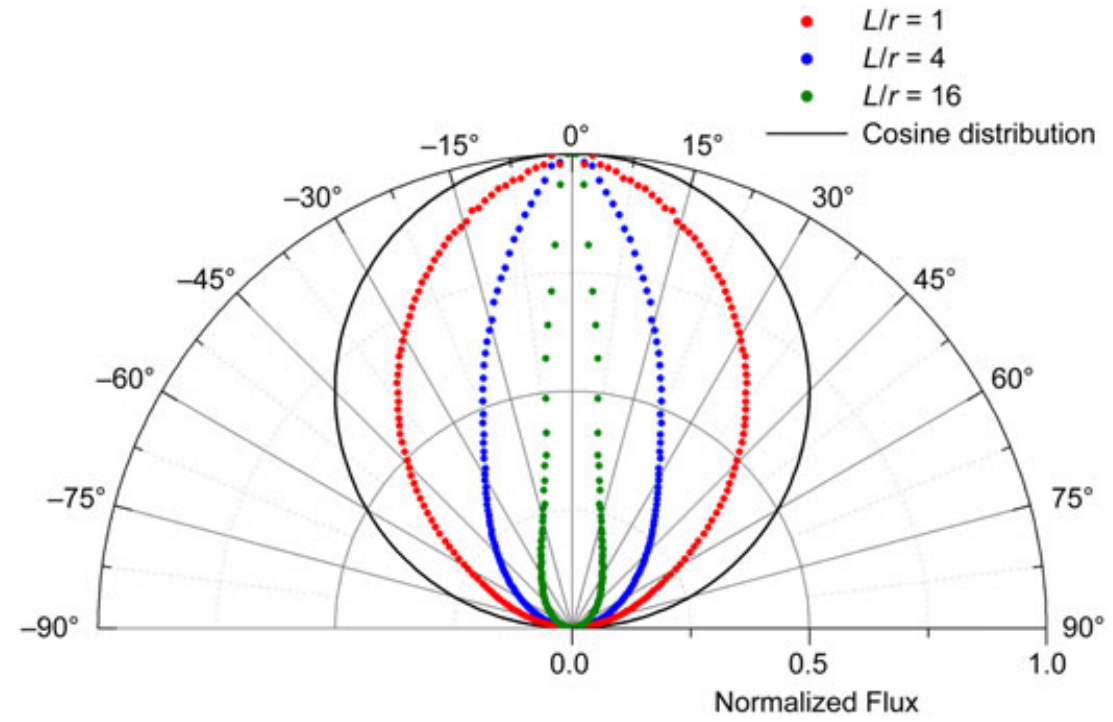

Figure 5. Cosine distribution emerging from a channel of different length-toradius ratio. Note the longer channels produce a more directed flow. [Color figure can be viewed at wileyonlinelibrary.com]

Table 1. Calculated properties for typical KEMS geometry at NASA Glenn $(l / d=2.67)$

\begin{tabular}{|lcllll|}
\hline \multicolumn{5}{c|}{ Input values } \\
\hline$L_{\text {pipe }}$ & $4 \mathrm{~mm}$ & $d_{\mathrm{A} 1}$ & $1 \mathrm{~mm}$ & $G$ & $25.0 \mathrm{~mm}$ \\
$d_{\text {pipe }}$ & $1.5 \mathrm{~mm}$ & $d_{\mathrm{A} 2}$ & $2 \mathrm{~mm}$ & $H$ & $37.7 \mathrm{~mm}$ \\
\hline
\end{tabular}

Simulation results

\begin{tabular}{|lcllll|}
\hline $\begin{array}{l}\text { Transmission } \\
\text { factor }\end{array}$ & \multicolumn{2}{c|}{$\begin{array}{c}\text { Average number } \\
\text { of collisions }\end{array}$} & \multicolumn{2}{c|}{$\begin{array}{c}\text { Percent with } \\
\text { no collisions }\end{array}$} \\
\hline$W_{\text {pipe }}$ & 0.2977 & $\bar{c}_{\text {pipe }}$ & 7.36 & $n c_{\text {pipe }}$ & 11.2 \\
$W_{\mathrm{A} 1}$ & $3.5 \times 10^{-4}$ & $\bar{c}_{\mathrm{A} 1}$ & 0.80 & $n c_{\mathrm{A} 1}$ & 86.4 \\
$W_{\mathrm{A} 2}$ & $1.6 \times 10^{-4}$ & $\bar{c}_{\mathrm{A} 2}$ & 0.34 & $n c_{\mathrm{A} 2}$ & 90.1 \\
\hline
\end{tabular}

An important point is that as long as the mass spectrometer only samples from a narrow solid angle normal to the plane of the orifice, the net flux measured by the spectrometer is not decreased by the channel orifice vs a knife edge orifice. The channel orifice has the advantage of producing a more directed flow and less chances for sampling the vapor from unwanted places.

\section{Calculated properties for a restricted collimation Knudsen effusion mass spectrometer}

Table 1 contains the calculated properties of the KEMS geometry used at NASA Glenn shown in Fig. 1(a) using $10^{8}$ simulated molecules. A1 and A2 refer to the lower and upper aperture, respectively. Only 11\% of molecules effusing directly from the pipe do not undergo any wall collisions. However, the additional collimating apertures, A1 and A2, increase the proportion of molecules passing directly from the source to the mass spectrometer ionizer to $90 \%$. As noted previously,
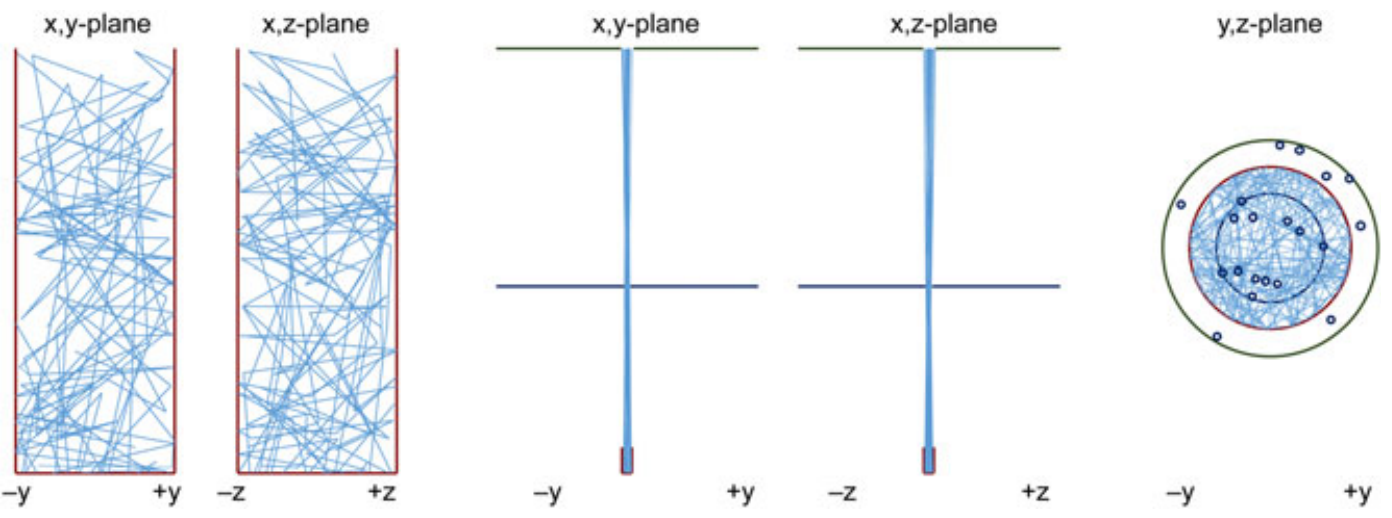

Figure 6. Views of the molecular trajectory from the vaporizing surface to the ionizer. Note that the circles indicate molecules that pass through the upper (source) aperture. [Color figure can be viewed at wileyonlinelibrary.com] 


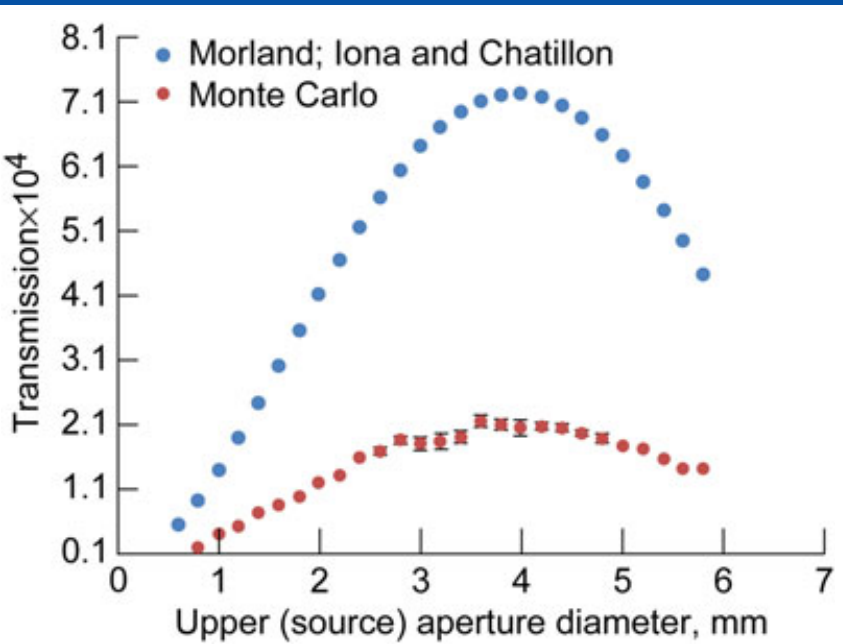

Figure 7. Transmission factor from vaporizing solid at bottom of cell orifice to upper aperture as a function of upper aperture diameter (and corresponding lower orifice diameter given in Table 2). [Color figure can be viewed at wileyonlinelibrary.com] selecting a narrow solid angle normal to the plane of the effusion orifice (as the two apertures do) gives an undiminished flux from a channel orifice making it similar to the a knife edge. And the channel orifice gives a more directed beam, which avoids cross-contamination in a multi-cell system.

Figures 6(a) to 6(c) show the views of the molecular path in a restricted collimation. In this simulation, $10^{6}$ molecules were run. For clarity only the first 50 molecular trajectories are traced. The vaporizing surface is at the bottom of the pipe. Figure 6(a) is a view of the trajectories in the pipe. Figure $6(b)$ is a view of the whole beam, showing only the molecules which make it out the upper aperture and Fig. 6(c) is a view from the above the upper aperture. The open circles are the molecules that made it through to the ionizer.

In Fig. 7, the results of this method are compared with those from the two analytical methods used by Chatillon and coworkers $^{[4-7]}$ to describe a restricted collimation system. The geometry they used was reproduced as close as possible for this calculation. The diameters of the two apertures are correlated due to the integration over the umbra, as described by Nuta and Chatillon. ${ }^{[6,7]}$ These are listed in Table 2 along

Table 2. Sampling geometry of Nuta and Chatillon ${ }^{[6]}$ and calculated transmission factors

\begin{tabular}{|c|c|c|c|c|c|}
\hline \multirow{2}{*}{$\begin{array}{l}\text { Upper } \\
\text { D-source }\end{array}$} & \multirow{2}{*}{$\begin{array}{l}\text { Lower } \\
\text { D-Field }\end{array}$} & \multicolumn{2}{|c|}{$\begin{array}{c}\text { Monte Carlo Transmission } \\
\text { Factor }\end{array}$} & \multirow{2}{*}{$\begin{array}{c}\text { Transmission Factor } \\
\text { Morland et al. }{ }^{[4]}\end{array}$} & \multirow{2}{*}{$\begin{array}{l}\text { Transmission Factor } \\
\text { Nuta and Chatillon } \\
{[6,7]}\end{array}$} \\
\hline & & Av Trans & St Dev & & \\
\hline 0.6 & 1.416 & $8.000 \mathrm{E}-06$ & $2.598 \mathrm{E}-06$ & 5.669E-05 & 5.669E-05 \\
\hline 0.8 & 1.377 & $2.050 \mathrm{E}-05$ & $2.598 \mathrm{E}-06$ & $9.534 \mathrm{E}-05$ & $9.535 \mathrm{E}-05$ \\
\hline 1 & 1.339 & $4.150 \mathrm{E}-05$ & $1.658 \mathrm{E}-06$ & 1.407E-04 & 1.407E-04 \\
\hline 1.2 & 1.300 & $5.550 \mathrm{E}-05$ & $2.958 \mathrm{E}-06$ & $1.911 \mathrm{E}-04$ & $1.911 \mathrm{E}-04$ \\
\hline 1.4 & 1.261 & 7.475E-05 & $1.479 \mathrm{E}-06$ & $2.448 \mathrm{E}-04$ & $2.448 \mathrm{E}-04$ \\
\hline 1.6 & 1.223 & $8.800 \mathrm{E}-05$ & $2.345 \mathrm{E}-06$ & $3.004 \mathrm{E}-04$ & $3.004 \mathrm{E}-04$ \\
\hline 1.8 & 1.184 & $1.000 \mathrm{E}-04$ & $1.581 \mathrm{E}-06$ & $3.565 \mathrm{E}-04$ & $3.565 \mathrm{E}-04$ \\
\hline 2 & 1.145 & $1.215 \mathrm{E}-04$ & 3.571E-06 & $4.118 \mathrm{E}-04$ & $4.118 \mathrm{E}-04$ \\
\hline 2.2 & 1.106 & $1.325 \mathrm{E}-04$ & $2.500 \mathrm{E}-06$ & $4.651 \mathrm{E}-04$ & 4.651E-04 \\
\hline 2.4 & 1.068 & $1.595 \mathrm{E}-04$ & $3.841 \mathrm{E}-06$ & $5.154 \mathrm{E}-04$ & $5.154 \mathrm{E}-04$ \\
\hline 2.6 & 1.029 & $1.700 \mathrm{E}-04$ & 5.339E-06 & $5.618 \mathrm{E}-04$ & $5.618 \mathrm{E}-04$ \\
\hline 2.8 & 0.990 & $1.873 \mathrm{E}-04$ & 5.494E-06 & $6.034 \mathrm{E}-04$ & $6.034 \mathrm{E}-04$ \\
\hline 3 & 0.952 & $1.818 \mathrm{E}-04$ & 9.311E-06 & 6.395E-04 & 6.395E-04 \\
\hline 3.2 & 0.913 & $1.845 \mathrm{E}-04$ & $1.258 \mathrm{E}-05$ & 6.695E-04 & 6.695E-04 \\
\hline 3.4 & 0.874 & $1.913 \mathrm{E}-04$ & $9.782 \mathrm{E}-06$ & $6.930 \mathrm{E}-04$ & $6.930 \mathrm{E}-04$ \\
\hline 3.6 & 0.835 & $2.163 \mathrm{E}-04$ & 8.899E-06 & 7.095E-04 & $7.096 \mathrm{E}-04$ \\
\hline 3.8 & 0.797 & $2.113 \mathrm{E}-04$ & 8.467E-06 & 7.189E-04 & 7.189E-04 \\
\hline 4 & 0.758 & $2.058 \mathrm{E}-04$ & $1.195 \mathrm{E}-05$ & 7.209E-04 & $7.210 \mathrm{E}-04$ \\
\hline 4.2 & 0.719 & $2.088 \mathrm{E}-04$ & $6.180 \mathrm{E}-06$ & $7.156 \mathrm{E}-04$ & 7.157E-04 \\
\hline 4.4 & 0.681 & $2.065 \mathrm{E}-04$ & 6.103E-06 & $7.030 \mathrm{E}-04$ & $7.029 \mathrm{E}-04$ \\
\hline 4.6 & 0.642 & $1.985 \mathrm{E}-04$ & 4.153E-06 & $6.834 \mathrm{E}-04$ & $6.835 \mathrm{E}-04$ \\
\hline 4.8 & 0.603 & $1.898 \mathrm{E}-04$ & 6.610E-06 & $6.569 \mathrm{E}-04$ & $6.569 \mathrm{E}-04$ \\
\hline 5 & 0.565 & $1.785 \mathrm{E}-04$ & 3.640E-06 & $6.241 \mathrm{E}-04$ & $6.242 \mathrm{E}-04$ \\
\hline 5.2 & 0.526 & $1.745 \mathrm{E}-04$ & 4.387E-06 & $5.855 \mathrm{E}-04$ & $5.857 \mathrm{E}-04$ \\
\hline 5.4 & 0.487 & $1.585 \mathrm{E}-04$ & $2.872 \mathrm{E}-06$ & $5.418 \mathrm{E}-04$ & $5.419 \mathrm{E}-04$ \\
\hline 5.6 & 0.448 & $1.430 \mathrm{E}-04$ & $1.871 \mathrm{E}-06$ & 4.936E-04 & 4.936E-04 \\
\hline 5.8 & 0.410 & $1.440 \mathrm{E}-04$ & $4.062 \mathrm{E}-06$ & 4.419E-04 & $4.420 \mathrm{E}-04$ \\
\hline \multicolumn{6}{|c|}{$\begin{array}{l}\text { Vaporizing solid: } 2.0-\mathrm{mm} \text { diameter at base of orifice. } \\
\text { Cell orifice: } 2.0-\mathrm{mm} \text { diameter; } 2.0 \text {-mm thickness. } \\
\text { Lower aperture: } 10 \mathrm{~mm} \text { from cell orifice. } \\
\text { Upper aperture: } 50 \mathrm{~mm} \text { from lower orifice. }\end{array}$} \\
\hline
\end{tabular}


with the transmission factors. Our transmission factors are presented as the average of four separate code runs with $10^{6}$ molecules each. The transmission factor, through the last aperture is plotted versus the source (upper) aperture diameter and corresponding field (lower) aperture diameter in Fig. 7.

The Monte Carlo calculations are about 3.5 at most lower than the analytical calculations of Chatillon and coworkers. ${ }^{[4-7]}$ The lack of smoothness in the Monte Carlo curve may be due to the relatively small sample size. Both the Monte Carlo and the analytical calculations show a maximum transmission at nearly the same upper and lower aperture diameter, suggesting that both approaches are useful for optimizing sampling geometry. The difference in absolute transmission factors is likely due to fundamental differences in the approaches. In Chatillon's method the integration over the penumbra/umbra does not capture the full cross-section of the orifice. This is important in their most recent calculations. ${ }^{[6,7]}$ Our method needs further refinement with larger sample sizes and consideration of scattering by background gases. Further study is needed to resolve the difference in absolute transmission. Nonetheless, the similar geometry dependence supports the validity of both approaches.

\section{CONCLUSIONS}

A Monte Carlo simulation allows for the fast and accurate simulation of basic Knudsen effusion mass spectrometry mass (KEMS) sampling geometries, allowing for the optimization of orifice sizes and spacings in a restricted collimation configuration in order to increase transmission and decrease the average number of collisions. This approach was verified with calculation of known transmission factors for simple cylindrical and rectangular orifices. The code has calculated angular distributions of molecules emerging from an orifice and has demonstrated the advantages of a cylindrical orifice to form a directed flow. It also demonstrates that restricted collimation samples directly from the cell vapor with the molecules sampled undergoing minimal orifice wall collisions. Finally, the calculations were compared with the analytical analyses of Chatillon and colleagues ${ }^{[4-8]}$ for a restricted collimation KEMS system. The two approaches give somewhat different absolute transmission factors, but similar geometry (aperture diameter) dependences.

\section{Acknowledgements}

We are grateful to Edward A. Sechkar, ZIN Technologies/ NASA Glenn Group, and Benjamin Kowalski, NASA Glenn, for assistance with the VBA code. Helpful discussions with Christian Chatillon and Iona Nuta, CNRS, SIMAP, Grenoble, France, are also appreciated. We are grateful to the NASA Transformational Tools and Technology project for funding.

\section{REFERENCES}

[1] J. Drowart, P. Goldfinger. Investigation of inorganic systems at high temperature by mass spectrometry. Angew. Chem. Int. Ed. 1967, 6, 581 .
[2] E. H. Copland, N. S. Jacobson. Measuring thermodynamic properties of metals and alloys with Knudsen effusion mass spectrometry. NASA/TP-2010-216795, 2010.

[3] W. A. Chupka, M. G. Inghram. Direct determination of the heat of sublimation of carbon with the mass spectrometer. J. Phys. Chem. 1955, 59, 100.

[4] P. Morland, C. Chatillon, P. Rocabois. High-temperature mass spectrometry using the Knudsen effusion cell. I. Optimization of sampling constraints on the molecular beam. High Temp. Mat. Sci. 1997, 37, 167.

[5] C. Chatillon, L.-F. Malheiros, P. Rocabois, M. Jeymond. High-temperature mass spectrometry with the Knudsen cell: II. Technical constraints in the multiple-cell method for activity determinations. High Temp-High Press 2002, $34,213$.

[6] I. Nuta, C. Chatillon. Knudsen cell mass spectrometry using restricted molecular beam collimation. I. Optimization of the beam from the vaporizing surface. Rapid Commun. Mass Spectrom. 2015, 29, 10.

[7] I. Nuta, C. Chatillon. Erratum to: "Knudsen cell mass spectrometry using restricted molecular beam collimation. I. Optimization of the beam from the vaporizing surface". Rapid Commun. Mass Spectrom. 2017, 31, 1077.

[8] J. W. T. Walsh. Radiation from a perfectly diffusing circular disc [Part I]. Proc. Phys. Soc. London, 1920, 32, 59.

[9] J. W. T. Walsh. Photometry. Constable \& Co., London, 1958, pp. 136-144.

[10] W. C. DeMarcus. The problem of Knudsen flow. Part 2. Solution of integral equation with probability kernels. Union Carbide and Carbon Corp., Oak Ridge, TN, 1956.

[11] R. T. Grimley, L. C. Wagner, P. M. Castle. Angular distributions of molecular species effusing from near-ideal orifices. J. Phys. Chem. 1975, 79, 302.

[12] D. H. Davis. Monte Carlo calculation of molecular flow rates through a cylindrical elbow and pipes of other shapes. J. Appl. Phys. 1960, 31, 1169.

[13] J. W. Ward, R. N. R. Mulford, R. L. Bivins. Study of some of the parameters affecting Knudsen effusion. II. A Monte Carlo computer analysis of parameters deduced from experiment. J. Chem. Phys. 1967, 47, 1718.

[14] J. W. Ward, M. V. Fraser. Some of the parameters affecting Knudsen effusion. IV. Monte Carlo calculations of effusion probabilities and flux gradients for Knudsen cells. J. Chem. Phys. 1968, 49, 3743.

[15] J. W. Ward, M. V. Fraser. Study of some of the parameters affecting Knudsen effusion. VI. Monte Carlo analyses of channel orifices. J. Chem. Phys. 1969, 50, 1877.

[16] J. W. Ward, R. L. Bivins, M. V. Fraser. Monte Carlo simulation of specular and surface diffusional perturbations to flow from Knudsen cells. J. Vac. Sci. Technol. 1970, 7, 206.

[17] J. W. Ward, M. V. Fraser, R. L. Bivins. Monte Carlo analysis of the behavior of divergent conical effusion orifices. J. Vac. Sci. Technol. 1972, 9, 1056.

[18] N. S. Jacobson. Diffusion of gases in capillaries. PhD thesis, Lawrence Berkeley Lab, 1981.

[19] M. J. Radke, N. S. Jacobson. Monte Carlo simulation of a Knudsen effusion mass spectrometer sampling system, NASA/TM-2016-219118, October, 2016.

[20] P. Clausing. The flow of highly rarefied gases through tubes of arbitrary length. J. Vac. Sci. Technol. 1971, 8, 636.

[21] D. J. Santeler. New concept in molecular gas flow. J. Vac. Sci. Technol. 1986, 4, 338.

[22] D. J. Santeler, M. D. Boeckmann. Combining transmission probabilities of different diameter tubes. J. Vac. Sci. Technol. A 1987, 5, 2493. 